\title{
FREIS: A WEB-BASED RESOURCES AND ENVIRONMENT INFORMATION SYSTEM FOR AGRO-ECOSYSTEM MANAGEMENT
}

\author{
Mingxin Men *, Yuepu Qi, Boyang Du, Hao Xu \\ College of Agricultural Resources and Environmental Sciences, Hebei Agricultural \\ University, Baoding, China, 071001 \\ * Corresponding author, Address: College of Agricultural Resources and Environmental \\ Sciences, Hebei Agricultural University, 215 Jianshe South Road, Baoding, 071001, P. R. \\ China, Tel: +86-312-7528231, Fax: +86-312-7528218, Email: menmingxin@sina.com
}

Abstract: Agro-ecosystem plays a crucial role in conserving biodiversity, sustaining ecosystem functions and processes, and maintaining land productive capacity. In order to effectively manage agro-ecosystem, the planners and government agencies are increasingly seeking better tools and techniques. In this paper, we describe the development of a Web-based resources and environment information system (FREIS), which helps to set up agricultural policy to improve productivity level and resource utility efficiency in terms of yield stability evaluation model. The system design involved four steps, the first was to set up a system platform for FREIS, then a spatial database was developed for analysis, after this the evaluation model was established, and lastly a Web-based interface with analysis tools was developed using client-server technology. FREIS provided a valuable technical scheme of the intelligent and comprehensive agricultural information management. The potential of a Webbased information system for agro-ecosystem management and challenges for its development was discussed.

Keywords: WebGIS; resources and environment information system; agro-ecosystem; productivity stability

Men, M., Qi, Y., Du, B. and Xu, H., 2008, in IFIP International Federation for Information Processing, Volume 259; Computer and Computing Technologies in Agriculture, Vol. 2; Daoliang Li; (Boston: Springer), pp. 891-898. 


\section{INTRODUCTION}

Agro-ecosystem is a man-made ecosystem under human intervention and control. It is a three dimensional ecosystem with the organic combination of nature, society and economic, and have the functions of energy flowing, material cycling, value and information transmission. It plays a crucial role in conserving biodiversity, sustaining ecosystem functions and processes, and maintaining land productive capacity (Zhao et al., 2003; Yang et al., 2005). The stability is one of important characteristics and is also the basis of maintaining higher the agricultural productivity and ensuring the ecosystem health development. In order to effectively manage agro-ecosystem, the planners and government agencies are increasingly seeking better tools and techniques. The appearance of GIS and other information technology makes all of these possible. People can use information technologies to access, store, disseminate different sources and spatio-temporal scale data, and analyze spatial variation (Tony, 1998; Jos et al., 1995; Issolah et al., 2001).

The history of Web-based GIS can be traced back to the development of the Xerox Map Viewer which used a Web Browser via HyperText Markup Language (HTML) format and Common Gateway Interface (CGI) programs to provide interactive mapping functions via the Internet (Putz, 1994). There is a great potential for using WebGIS in the areas of natural resources management and environmental assessment and monitoring. A web-based system was constructed to supply farmers and agricultural advisers with justin-time information and decision support for crop management (Allan et al., 2000). A web-based system was developed to advise on the relative efficacy of different for mixes of weed and crop species at different times of the year in a forestry of farm forestry setting (Alan et al., 2004). A web-based environmental decision support system was developed for environmental planning and watershed management, which integrated the spatial analysis model into ArcIMS based on the client/server model (Ramanathan et al., 2004). A prototype web site has been developed to provide easy access of geospatial information and to facilitate Web-based image analysis and change detection capabilities for natural resource managers and regional park rangers (Tsou, 2004).

In this paper, the main object was to develop an interactive web-based resources and environment information system using ArcIMS, geodatabase and internet technology in Hebei Province of China. The information system integrated agricultural productivity stability model to analyze the productivity fluctuation trends. The main function of the FREIS is to provide map and data query for the agro-ecosystem manager and the planner, and the technology support to the ecosystem management. 


\section{FREIS CONSTRUCTION}

WebGIS is the realization of GIS functions on Web $\mathrm{s}$ through integration of Internet and GIS. It provides the functions of browsing spatial data and thematic maps and analyzing the spatial data on Web with the browser. As one of the ESRI's WebGIS products, ArcIMS which uses Java Applet, Java Servlet and XML application technology can obtain dynamic Map, GIS data and various service items. The system in this study uses ArcIMS as the WWW based GIS server. As a result of the working environment of ArcIMS is in Java, the components of Web Server, Java virtual machine (JVM) and Servlet Engine are required to guarantee ArcIMS operation normally. So the system uses Microsoft Internet Information Server (IIS6.0) as Web Server, J2SDK1.4.2.06 as Java virtual machine (JVM) and ServletExec as Servlet Engine. The FREIS design is based on the browser/server mode in which clients send requests to services running on a server and receive appropriate information in response. The browser/server used in this study has a threetiered configuration: a WWW client of Microsoft Internet Explorer (IE), a WWW server of Microsoft Internet Information Server (IIS) and a WWW based GIS server of ArcIMS (Fig. 1).

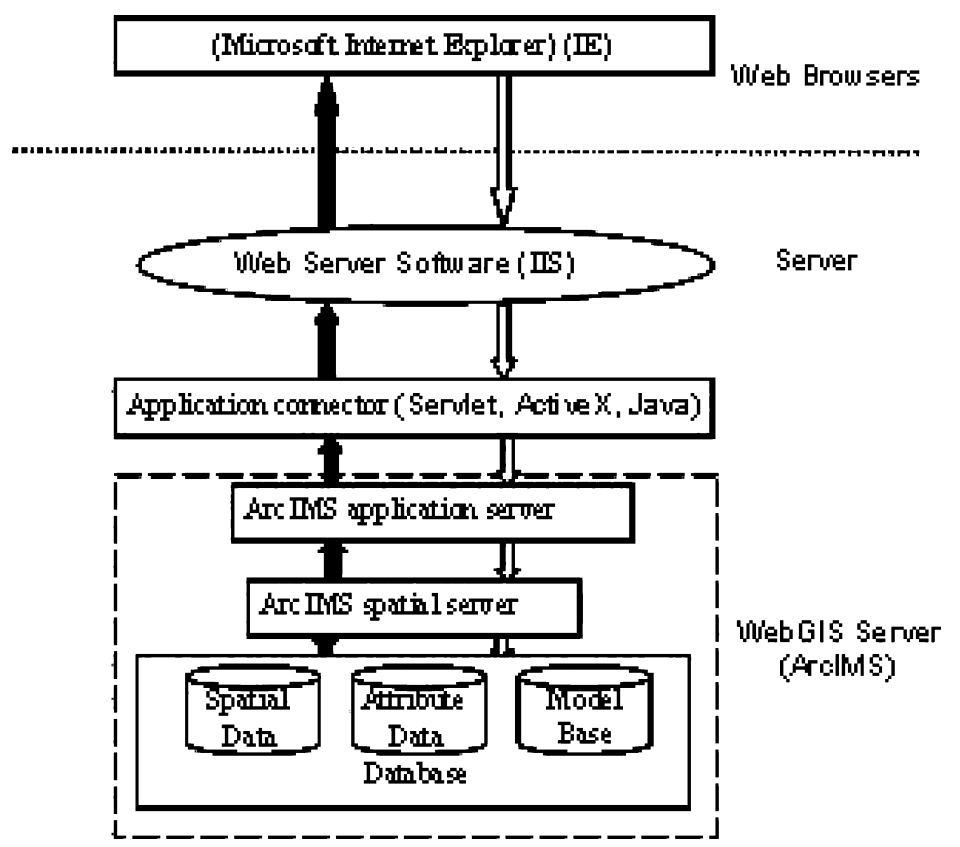

Fig. 1. The process of information transfer between client and server

It shows the flow of information in the client-server transaction. At first, the users initiate a request to the Web Server by manipulating tools and buttons in the browser. The Web server passes the request to the application connector. Then, the application connector translates the request to the 
ArcXML and passes the ArcXML to ArcIMS Application Server. ArcIMS Application Server processes loading distribution and passes the request to ArcIMS spatial server. There are seven types of ArcIMS spatial server, such as image, feature, query, geocode, extract, metadata and ArcMap. Among of these images, ArcMap, feature and metadata can access the spatial server. The access isn't direct but through virtual server Tools. At last, ArcIMS spatial server gives a corresponding response after receiving the request, and passes the results to ArcIMS Application Server in opposite direction. The Web server displays the querying outputs on HTML pages. The Web browser on the client machine displays the results and supports further user interaction, which creates additional requests. The whole process makes up of a request/response Cycle.

\section{DATABASE DESIGN}

\subsection{Database Manage System}

FREIS uses geodatabase model to create an object-oriented spatial database. We used Oracle9i and ArcSDE to customize our spatio-temporal database. ArcSDE is an advanced spatial data service software produced by ESRI. All of the client programs can use it, such as ArcIMS and ArcGIS Desktop. ArcSDE provides a gateway to store, manage and use the spatial data. The RDBMS can be extended to store spatial data through it (Fig. 2).

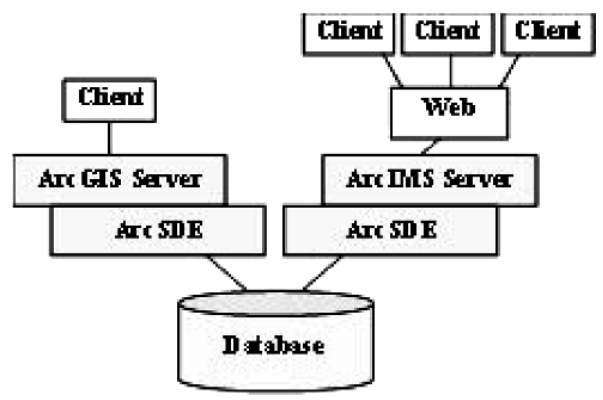

Fig. 2. Sketch map of DBMS framework

Geodatabase model was used to integrate the attribute and behavior of the spatial objects. The attribute of the feature class have natural action, and any type of the relationships can be defined in Geodatabase model. The data is oriented to the users in it. As compared with previous spatial data model, the relation and attribute with behavior had greatly extended the data representation ability. And the new model allows users use the regulations to define the more GIS applications. The excellence of the model is that the 
feature class completely stored in one database. Therefore the large scale geographic features can be stored smoothly. Using the Geodatabase model, the feature was a record in the database. Thus the physical and logical data model was more adjacency. The data object in Geodatabase, which realized mostly customization without compiling any code, was generally consistent to the object which was defined in logical data model. It uses the field, virtual regulation and other functions to do this.

\subsection{Data in FREIS}

The data of FREIS includes of the spatial data and attribute data. The spatial data is mainly the vector maps which compose of the basic spatial database and the results maps. The spatial database includes administrative maps, soil type maps, organic matter distribution maps, rainfall distribution maps, topographical maps with different scale etc. Attribute data included natural data and social and economic data and was shown in Table 1.

Table 1. Data of Agricultural Resource and Environment Information System

\begin{tabular}{ll}
\hline Data Type & Data Name \\
\hline \multirow{3}{*}{ Spatial Data } & Administrative Map of Hebei \\
& Soil Types Map of Hebei \\
& Organic Matter Distribution Map of Hebei \\
& Rainfall Distribution Map of Hebei \\
& Topographical Map of Hebei \\
& Agro-ecosystem Stability Value Map of Hebei \\
& Crop Production Fluctuation Value Map \\
& Agro-ecosystem Stability Grade Map \\
\hline & Meteorological Data \\
& Soil Properties Data \\
& Social and Economic Data \\
\hline
\end{tabular}

\section{STABILITY EVALUATION MODEL}

At first, agro-ecosystem stability indicators were determined through AHP model. Then, the weight and standardization index was calculated with the Z-Score method. At last the integrated index was calculated. The value of agro-ecosystem productivity stability (API) is a synthetic evaluation results of the multilevel system. According to its characteristic, we choose the linear weighted suming method in the study. The formula is:

$$
A P I=\frac{\sum w_{i}^{*} x_{i}}{100 \sum w_{i}}
$$


Where: $A P I$ is comprehensive index; $W i$ is weight index; $X i$ is value of single standardization index.

The stability evaluation model was store in model bases of FREIS and was integrated to the user interface. The clients can use ArcIMS server to transfer it.

\section{INTERFACE AND APPLICATION}

The functions of FREIS include displaying of the map, consulting service and statistics and information outputting etc. The interface is shown in Fig. 3.

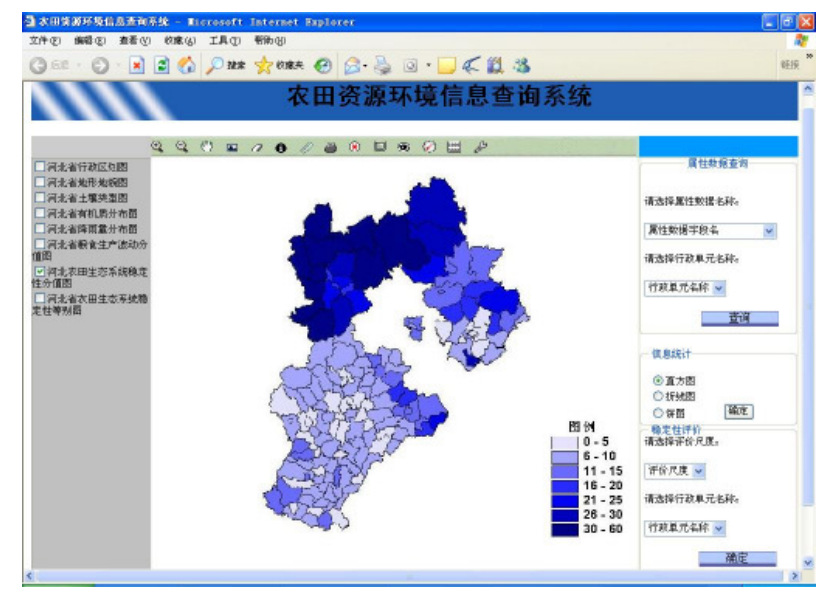

Fig. 3. The main function interface of FREIS

\subsection{Map Displaying}

Users can display and analyze data in the interactive interface. The GIS data browsing tools of FREIS created by ArcIMS is standard, such as zooming out, zooming in, panning, zooming to full extent, refresh, distance and area measuring, etc. These tools provide interactive operations between the users and the maps. The buttons of panning, zooming in or out allow the user to move around in the map displaying and change the maps scale. Full screen button allows the map come back to full screen display at any scale display. The distant measuring button allows user to measure the distant from one point to another on the map. Users also can use the area measure button to draw the outline of polygon to measure its area.

The left of the interface is displaying frame of the map layers. Users can point the button in the check box to show the map layers. The middle of the interface is map displaying window that can show the maps in different 
scale. The right of the interface is query tools of attribute data and statistic tools. Users can select different area and attribute name to query basic data. The information statistic tools allow users do basic statistical function.

\subsection{Statistic Information Output}

The functions of information statistic and consultation service were the main function. FREIS can display and output information based on the spatial database. Users can select different regions and attribute names to complete the data query. Users can do basic statistics by using chart tools. (Fig. 4). Output function of FREIS allows users to output the information using digital table and papery documents.

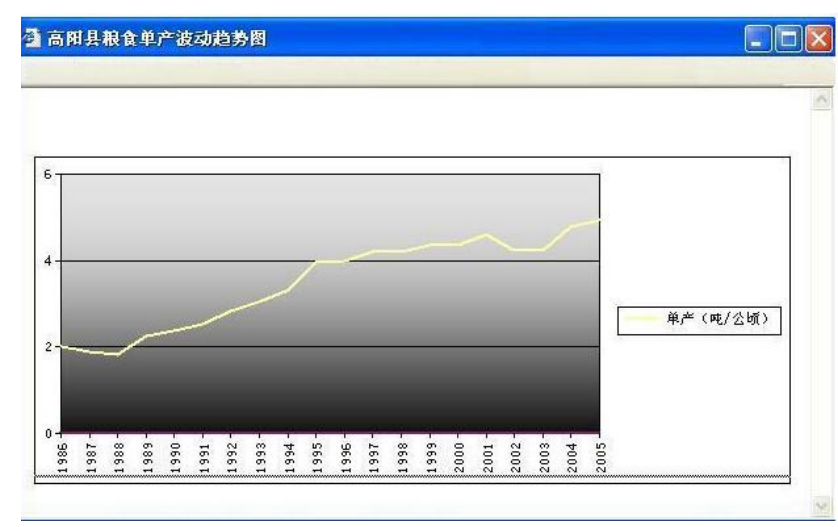

Fig. 4. Statistic chart

\subsection{Stability Evaluation}

On the right-down of the interface is the stability evaluation tool. Users can select different regions to evaluate the agro-ecosystem productivity stability. After pointing the stability evaluation tools, the results will be shown. This tool can evaluate the productivity stability in different scales.

\section{CONCLUSION AND DISCUSSION}

FREIS, a Web-based system developed for this project, provides the users with a simple information query tool. This system can be used by planners and mangers within local government, the general public, environmental analysts, farmland researchers and other interested parties. Users can know more to the agro-ecosystem by using FREIS. The FREIS has a lot of limitation now. First, it can not completely describe the agro-ecosystem, because of the data is imperfect and the influence factors of the agro- 
ecosystem are more complicated. It should be perfected from collected more information. FREIS can evaluate the productivity stability of agro-ecosystem of Hebei Province. But this model has not been validated in practice. In the future, based on feedbacks received from users, we hope to revise and perfect the model constantly. In addition, the data spatial scopes is also limited. It only includes basic information of Hebei Province. We must collect more spatial data to extend it. WebGIS has the potential to share data, provide easy access for users with limited GIS knowledge, and assemble data and information customized for specific topics. The information system based on internet technology provided a customizable interface to users to organize the data and information. The WebGIS will be the development trend of natural resources and environment information system in Future.

\section{ACKNOWLEDGEMENTS}

This study has been funded by China National 973 Plans Projects (Contract Number: 2005CB121107).

\section{REFERENCES}

Alan J T, Ian W. A web-based expert system for advising on herbicide use in Great Britain. Computers and electronics in Agriculture, 2004, 42: 43-49.

Allan L J, Peter S, Boll I T, Pathak B K. P1@nteInfo®-a web-based system for personalized decision support in crop management. Computers and Electronics in Agriculture, 2000, 25 : 271-293.

Issolah R, Giovannetti J F. The Algerian agricultural information and document system: how does it support national research and training. International Journal of Information Management, 2001, 21: 289-299.

Jos A A, Ruud B, Huirne M, Aalt A D. Economic value of management information systems in agriculture: a review of evaluation approaches. Computers and Electronics in Agriculture, 1995, 13: 273-288.

Putz S. Interactive Information services using World Wide Web Hypertext. In Proceedings of the First International Conference on the World Wide Web, 1994, 25-27.

Ramanathan S, James C M, Jim D. A Web-based environmental decision support system (WEDSS) for environmental planning and watershed management. Geograph Syst, 2004, 6: 307-322.

Tony L. Evolution of farm management information Systems. Computers and Electronics in Agriculture, 1998, 19: 233-248.

Tsou M H. Integrating Web-based GIS and image processing tools for environmental monitoring and natural resource management Geograph Syst, 2004, 6: 155-174.

Yang Z X, Zheng D W, Wen H. Studies on service value evaluation of agricultural ecosystem in beijing region. Journal of Natural Resources, 2005, 20: 564-571 (in Chinese).

Zhao R Q, Huang A M, Qin M Z. Study on farmland ecosystem service and its valuation method. System Sciences and Comprehensive Studies in Agriculture, 2003, 19: 267-270 (in Chinese). 